\title{
Effect of lifestyle, medication and ethnicity on cardiometabolic risk in the year following the first episode of psychosis: prospective cohort study
}

Fiona Gaughran*, Daniel Stahı*, Dominic Stringer, David Hopkins, Zerrin Atakan, Kathryn Greenwood, Anita Patel, Shubulade Smith, Poonam Gardner-Sood, John Lally, Margaret Heslin, Brendon Stubbs, Stefania Bonaccorso, Anna Kolliakou, Oliver Howes, David Taylor, Marta Di Forti, Anthony S. David, Robin M. Murray†, Khalida Ismail† and the IMPACT team

\section{Background}

The first episode of psychosis is a critical period in the emergence of cardiometabolic risk.

\begin{abstract}
Aims
We set out to explore the influence of individual and lifestyle factors on cardiometabolic outcomes in early psychosis.
\end{abstract}

\section{Method}

This was a prospective cohort study of 293 UK adults presenting with first-episode psychosis investigating the influence of sociodemographics, lifestyle (physical activity, sedentary behaviour, nutrition, smoking, alcohol, substance use) and medication on cardiometabolic outcomes over the following 12 months.

\section{Results}

Rates of obesity and glucose dysregulation rose from $17.8 \%$ and $12 \%$, respectively, at baseline to $23.7 \%$ and $23.7 \%$ at 1 year. Little change was seen over time in the $76.8 \%$ tobacco smoking rate or the quarter who were sedentary for over $10 \mathrm{~h}$ daily. We found no association between lifestyle at baseline or type of antipsychotic medication prescribed with either baseline or 1-year cardiometabolic outcomes. Median haemoglobin $\mathrm{A}_{1 \mathrm{c}}\left(\mathrm{HbA}_{1 \mathrm{c}}\right)$ rose by 3.3 $\mathrm{mmol} / \mathrm{mol}$ in participants from Black and minority ethnic (BME) groups, with little change observed in their White counterparts. At 12 months, one-third of those with BME heritage exceeded the threshold for prediabetes $\left(\mathrm{HbA}_{1 \mathrm{c}}>39 \mathrm{mmol} / \mathrm{mol}\right)$.

\section{Conclusions}

Unhealthy lifestyle choices are prevalent in early psychosis and cardiometabolic risk worsens over the next year, creating an important window for prevention. We found no evidence, however, that preventative strategies should be preferentially directed based on lifestyle habits. Further work is needed to determine whether clinical strategies should allow for differential patterns of emergence of cardiometabolic risk in people of different ethnicities.

\section{Declaration of interest}

F.G. has received honoraria for advisory work and lectures or CME activity support from Roche, BMS, Lundbeck, Otsuka, Janssen and Sunovion, is a collaborator on an NHS Innovations project co-funded by Janssen and has a family member with professional links to Lilly and GSK, including shares. R.M.M. has received honoraria for lectures from Lundbeck, Otsuka, Janssen and Sunovian. M.D.F. has received honoraria for lectures from Janssen and Sunovian. Z.A. has received honoraria for advisory work and lectures from Roche, Sanofi, Lilly and Otsuka. O.H. has received investigator-initiated research funding from and/or participated in advisory/speaker meetings organised by AstraZeneca, Autifony, Biogen, BMS, Eli Lilly, Heptares, Jansenn, Lundbeck, Lyden-Delta, Otsuka, Servier, Sunovion, Rand and Roche. D.T. has received funding for lectures and research from Janssen, Otsuka, Servier, Lundbeck, Sunovion.

\section{Keywords}

First episode psychosis; cardiometabolic risk; weight; glucose dysregulation; ethnicity.

\section{Copyright and usage}

(C) The Royal College of Psychiatrists 2019. This is an Open Access article, distributed under the terms of the Creative Commons Attribution-NonCommercial-ShareAlike licence (http://creative commons.org/licenses/by-nc-sa/4.0/), which permits noncommercial re-use, distribution, and reproduction in any medium, provided the same Creative Commons licence is included and the original work is properly cited. The written permission of Cambridge University Press must be obtained for commercial re-use.
People with psychotic illnesses die prematurely, mostly from natural causes, with markedly raised standardised mortality ratios for cardiovascular disease (CVD, 3.6, 95\% CI 3.5-3.6), with young adults (4.5, 95\% CI 4.1-4.8), women (4.6, 95\% CI, 4.5-4.7) and people of White ethnicity $(4.9,95 \% \mathrm{CI}, 4.8-5.0)$ especially at risk. Cardiometabolic dysregulation is evident even from the early stages of psychosis ${ }^{2}$ and increases in the months after first presentation, with olanzapine having the most marked effect. ${ }^{3}$ Clozapine also affects metabolism, with 55\% exhibiting glucose dysregulation within 3 months of starting. ${ }^{4}$ A recent meta-analysis reported that antipsychotics were associated with greater weight gain in Asian as opposed to Western studies, although very few studies looked

* These authors contributed equally to the work as first authors. † These authors contributed equally to the work as last authors. $\neq$ Members of the IMPACT team are listed in the Acknowledgements. directly at the effects of ethnicity. ${ }^{5}$ Evidence is needed to determine whether or not interventions to modify cardiometabolic risk can be targeted in first-episode psychosis (FEP). Few studies have investigated whether health behaviours at presentation including diet, physical activity and substance use predict subsequent deterioration in cardiometabolic status. An exception is a recent prospective study of 101 people with $\mathrm{FEP}^{6}$ that found that low aerobic fitness was a significant risk factor for metabolic syndrome. Overall, however, insufficient prospective observational studies have attempted to disentangle the impact of lifestyle on the emergence of cardiometabolic risk to reliably inform the development and targeting of effective preventative strategies.

The main aims of this study were therefore to (a) to determine the prevalence of cardiometabolic risk factors in an ethnically diverse population at first presentation with psychosis; (b) to describe the emergence of additional cardiometabolic risk over 
the year following first presentation with psychosis and (c) to determine the relationship between lifestyle factors (diet, sedentary behaviour, smoking, substance use) and antipsychotic medication, in particular olanzapine and clozapine use, on cardiometabolic risk both at baseline and at 12-month follow-up. We hypothesised that there would be an association between baseline lifestyle choices and (a) cardiometabolic risk at baseline and (b) prospectively in change in cardiometabolic risk over a 1-year follow-up period. We also hypothesised that the emergence of glucose and lipid dysregulation would be greater in those prescribed the dibenzodiazepines, clozapine or olanzapine, compared with other antipsychotics.

\section{Method}

\section{Setting and design}

A prospective observational cohort of people was followed up for 12 months after their first presentation with psychosis. The study took place in in-patient and early intervention in psychosis community mental health teams in three English mental health National Health Service (NHS) services.

\section{Eligibility criteria}

Inclusion criteria were as follows: (a) aged between 16 and 65 years; (b) within 6 months of first presentation with psychosis (ICD-10 codes F20-29 and F30-33); (c) proficient in English with no requirement for an interpreter. Patients were excluded if they were pregnant or had a major medical illness or neurological disease; had been diagnosed with a severe intellectual disability; had an organic cause for their psychosis; or had previous contact with health services for the presence of psychosis. All participants were included in the study only after giving written, confirmed consent. The study protocol was approved by the Joint South London and Maudsley and the Institute of Psychiatry NHS Research Ethics Committee (08/H0807/53).

\section{Assessments}

Patients were assessed at baseline and after 12 months. Sociodemographic data were recorded at baseline, namely age, gender, ethnicity (self-report) and years of education. The operational criteria checklist for psychotic and affective illness (OPCRIT) was used to assess type of mental health state over the lifetime. ${ }^{8}$ All other measures were recorded at both time points. Selected clinical measures unaffected by fasting state (weight, blood pressure, haemoglobin $\mathrm{A}_{1 \mathrm{c}}\left(\mathrm{Hb}_{1 \mathrm{c}}\right)$, cholesterol, highdensity lipoprotein (HDL)) were recorded where available and utilised in analyses at baseline if the relevant measure post-dated the onset of psychosis and preceded the research measures, being thus less likely to have been affected by the introduction of psychotropic medication. Follow-up clinical measures were utilised if research measures for that period were missing.

\section{Psychopathology}

Mental health status was measured using the Positive and Negative Symptom Scale, ${ }^{9}$ Global Assessment of Functioning, ${ }^{10}$ Clinical Global Impression Scale, ${ }^{11}$ Calgary Depression score, ${ }^{12}$ and the Young Mania Rating Scale. ${ }^{13}$

\section{Pharmacological history}

Type(s) (British National Formulary definitions) of psychotropic medication and duration of antipsychotic (in days) were retrospectively extracted from electronic medical records.

\section{Cardiometabolic measures}

Metabolic measures comprised anthropometric measures of weight, height, body mass index (BMI), waist circumference and blood pressure, as well as fasting blood samples for glucose, glycated haemoglobin (HbA1c), lipids and C-reactive protein (CRP). Standardised techniques were used to measure height, blood pressure and weight. Where available, the blood pressure values are the second blood pressure measurements (first reading presented in $75 / 219$ participants at baseline; and $39 / 147$ at 12 months). Waist circumference was measured at the umbilicus with the patient standing.

Obesity was defined by the World Health Organization $(\mathrm{WHO})^{14}$ reference standard $\left(\mathrm{BMI} \geq 30 \mathrm{~kg} / \mathrm{m}^{2}\right)$ and overweight as BMI $\geq 25 \mathrm{~kg} / \mathrm{m}^{2}$. Diabetes was diagnosed based on a $\mathrm{HbA}_{1 \mathrm{c}}$ of $\geq 48 \mathrm{mmol} / \mathrm{mol}$ ( $\geq 6.5 \%$ ), or a fasting glucose $\geq 7.0 \mathrm{mmol} / \mathrm{L}$ or a prior diagnosis of diabetes. In keeping with recent guidance from the American Diabetes Association, an $\mathrm{HbA}_{1 \mathrm{c}}$ of $39-47$ $\mathrm{mmol} / \mathrm{mol}(5.7-6.4 \%)$ was taken to indicate glucose dysregulation or a high risk of diabetes. ${ }^{15}$ The International Diabetes Federation definitions of other cardiometabolic risk factors were used. ${ }^{16}$ Insulin resistance was presented using the homeostasis model assessment - insulin resistance (HOMA-IR), calculated from fasting glucose and insulin levels. Inflammation was estimated using high-sensitivity CRP as a marker.

\section{Physical activity and dietary intake}

Physical activity was assessed by the International Physical Activity Questionnaire, ${ }^{17}$ which has been validated in psychosis. ${ }^{18}$ The selfreport Dietary Instrument for Nutrition Education (DINE) ${ }^{19}$ was used to assess dietary patterns over the previous week. Additional questions were included to account for sugar intake, the consumption of take-away food, carbonated drinks and adding either salt or sugar to food/drinks.

\section{Substance use}

Cigarette and tobacco consumption were measured using the Nicotine Dependence questionnaire ${ }^{20}$ and alcohol use with the Alcohol Use Disorders Identification Test (AUDIT), ${ }^{21}$ where scores of eight or more indicate hazardous and harmful alcohol use. A modified Cannabis Experience Questionnaire (CEQ-4) was used to enquire about lifetime and current use of substances ${ }^{22,23}$ and a urine drug screen requested.

\section{Statistical analysis}

Descriptive data are presented in tabular form. Pairwise comparisons were done using $t$-tests for continuous and $\chi^{2}$ tests for categorical outcomes. Baseline associations between continuous scores for lifestyle and cardiometabolic factors were investigated using unadjusted and adjusted linear regression models. To account for different patterns of missingness, we used multiple imputation by chained equations prior to these analyses, using the lifestyle factors (DINE saturated fat score, AUDIT hazardous drinking score, number of h sitting per day and whether taking olanzapine), cardiometabolic factors (cholesterol, diastolic blood pressure, $\mathrm{HbA}_{1 c}$, waist circumference, BMI, HDL and triglycerides), age, gender, ethnicity and pre-baseline number of days on antipsychotic medication in the multiple imputation model. We used the 'mi impute chained' command in Stata version 15.1, with 50 imputed data-sets for each multiple imputation model. Binary variables were imputed using logistic regression, using augmented logistic regression where perfect prediction was detected. ${ }^{24}$ Continuous variables were imputed using linear regression unless they appeared 
non-normal, in which case the predictive mean matching imputation method, drawing from five nearest neighbours, was used. ${ }^{25}$

Imputed data-sets were then used to examine cross-sectional associations between each lifestyle factor and cardiometabolic factor separately using linear regression, unadjusted and adjusted for prespecified potential confounders of CVD risk, namely age, gender, ethnicity and pre-baseline number of days on antipsychotic medication. We further explored the cross-sectional associations between use of dibenzodiazepine medications (yes/no) prior to baseline and cardiometabolic factors at baseline using the same model and potential confounders.

For each outcome (change in cardiometabolic factor) at 12 months we employed separate multiple imputation models (using the same method as above) using the outcome and the same variables at baseline. We then explored for each baseline lifestyle factor, separately, whether they were associated with change in cardiometabolic factors over the 12-month follow-up period, unadjusted, and then adjusted for the above potential confounders, investigating associations between use of dibenzodiazepine medications between baseline and 12 months (yes/no) and cardiometabolic factors in the same way.

We separately assessed whether cardiometabolic factors at baseline differed between (a) participants taking medication with less or greater than 14 days of antipsychotic medication prior to baseline and (b) participants who were taking medication and those who were unmedicated prior to baseline.

To account for multiple testing a stricter alpha of 0.01 was prespecified as the significance level. ${ }^{26}$ Tests with a $P$-value between 0.01 and 0.05 were discussed as a trend and conclusions should be treated as explorative. Sensitivity analyses were carried out for all the analyses using complete cases from the full data-set, and also using a reduced data-set (with only participants with $<5$ variables of interest missing) prior to using multiple imputation to check the extent to which the original multiple imputation was plausible.

\section{Results}

We screened 11705 people for eligibility; 971 were eligible of whom 321 (33.1\%) consented to participate (263 declined, 50 transferred, 337 uncontactable). Twenty-eight were excluded after consent when further information became available, leaving 293 eligible people, (mean age 30.6 years (s.d. $=10.5)$ ) in the study at baseline, $46.4 \%$ of whom were of White ethnicity; 36.9\% Black and 7.8\% Asian. Sixteen withdrew at baseline, and 251 completed baseline measures with 26 remaining in the study but missing or declining data collection at that time point. A further 10 participants withdrew during the study, 1 died and 140 dropped out (51 uncontactable, 73 declined, 11 missed and 5 in prison), with 125 completing 12month follow-up assessments. Demographic and clinical characteristics are reported in supplementary Table 1 available at https://doi. org/10.1192/bjp.2019.159.

Twelve-month follow-up was completed for 125 patients with additional selected anthropometric and blood measures taken from clinical records where available and required. There were no differences in baseline demographics or cardiometabolic measures between those who had 12-month follow-up assessments ( $n=$ $125)$ and those who did not $(n=168)$ (supplementary Table 4$)$.

\section{Cardiometabolic and lifestyle factors in the year following onset of psychosis}

Rates of obesity, hypertriglyceridaemia, diabetes, raised CRP and low HDL cholesterol all rose over the first year of illness, and the proportion of people with $\mathrm{HbA}_{1 \mathrm{c}}$ in the glucose dysregulation range almost doubled (Tables 1 and 2, supplementary Tables 2 and 7 and Fig. 1) Rates of tobacco smoking were high (Tables 2 and 3); smokers consumed a median of ten cigarettes per day, with little change over time. Combining both self-report and urinary drug screen data, $49.5 \%(102 / 206)$ of participants were current users of cannabis at baseline, and 23/183 (12.6\%) reported current usage of 'other recreational drugs'. The corresponding figures at 12 months were $38.1 \%(40 / 105)$ and $12 / 102(11.8 \%)$, respectively. From baseline to 12 months, 12 (11.3\%) participants initiated cannabis use while 16 (15.5\%) stopped using cannabis.

Data were available on antipsychotic prescriptions prior to baseline for $242(82.6 \%)$ participants. In total 22\% (54/242) were antipsychotic-free before baseline, and a further 65 (26.9\%) had received antipsychotics for less than 2 weeks. The median duration of antipsychotic treatment for those prescribed antipsychotics prebaseline was 21 days (interquartile range $(\mathrm{IQR})=9.0-55.5$ days) (mean 43.3 days $($ s.d. $)=53.3)$, with most $(94.7 \% ; n=178 / 188)$ prescribed second-generation antipsychotics. Overall, 128 people were prescribed olanzapine across the year, 102 as their first antipsychotic. Of those on olanzapine at baseline $(n=89$; median dose $10 \mathrm{mg}$ (IQR = 10-75; range 2.5-25)), 71\% (52/73) remained on olanzapine at follow-up.

At follow-up, 66 people were prescribed olanzapine (we had dose data of 45 people), at a median dose of $12.5 \mathrm{mg}(n=45$, IQR $=10-17.5$; range 2.5-30). All bar 15 had been prescribed antipsychotic medication over the course of the study, for a median of $378(\mathrm{IQR}=302-434)$ days (mean of 354.6 (s.d. = 138.9) days), with those receiving olanzapine prescribed it for a median of 236 $(\mathrm{IQR}=61-388)$ days (mean of 239.6 (s.d. $=169.8)$ days). No patients were prescribed clozapine. We did not have data on somatic medications prescribed over the course of the follow-up.

Participants taking medication prior to baseline had higher baseline average waist circumferences $(+7.7 \mathrm{~cm}, 95 \%$ CI 2.0-13.4; $P=$ 0.009) compared with those unmedicated. Those who had received over 2 weeks antipsychotic medication prior to baseline had higher total cholesterol $(+0.5 \mathrm{mmol} / \mathrm{L}, 95 \%$ CI $0.1-0.8 ; P=0.007)$ than those prescribed antipsychotics for less than 2 weeks (excluding those prescribed no antipsychotic) (supplementary Table 3).

At baseline, 57\% consumed a carbonated drink daily, half (50\%) drinking more than one $500 \mathrm{~mL}$ bottle per day and $21.4 \%$ of the total sample drank diet carbonated drinks daily. Threequarters $(75.7 \%)$ consumed tea on a daily basis, most (90.8\%) drinking more than one cup, with $44 \%$ of the sample adding 2 teaspoons or more of sugar to each cup of tea. Salt was added to food during cooking by $66.5 \%$ of participants. A total of $78.5 \%$ consumed take-away meals, three-quarters of whom (75.8\%) did so more than once weekly.

\section{Relationship between lifestyle/medication and cardiometabolic outcomes at baseline and 12-month follow-up.}

Baseline DINE fat scores, sedentary behaviour, AUDIT scores and pre-baseline olanzapine use were not significantly associated with any of the baseline cardiometabolic outcomes either unadjusted or after adjusting for potential confounders (supplementary Table 6). Nor did the linear regression models show any association between baseline lifestyle factors and change in any of the cardiometabolic outcomes over 12 months either unadjusted or after adjusting for potential confounders (Table 4). Nor was there evidence of a difference in change in cardiometabolic outcomes by 12 months in those participants prescribed olanzapine between baseline and 12 months and those not prescribed olanzapine (unadjusted and adjusted) (Table 4). 


\begin{tabular}{|c|c|c|c|c|c|c|}
\hline & \multicolumn{3}{|c|}{ Baseline } & \multicolumn{3}{|c|}{12 months } \\
\hline & $n$ & Mean & s.d./IQR & $n$ & Mean & s.d./IQR \\
\hline Waist circumference (cm), men & 102 & 90.2 & 12.1 & 66 & 93.4 & 13.7 \\
\hline Waist circumference $(\mathrm{cm})$, women & 59 & 88.8 & 16.1 & 44 & 89.8 & 16.8 \\
\hline Systolic blood pressure (mm/Hg) & 219 & 117.4 & 15.6 & 147 & 118.4 & 15.6 \\
\hline Diastolic blood pressure (mm/Hg) & 219 & 75.0 & 12.0 & 147 & 77.4 & 12.0 \\
\hline Cholesterol (mmol/L) & 186 & 4.8 & 1.0 & 114 & 4.8 & 1.1 \\
\hline High density lipoprotein (mmol/L) & 179 & 1.4 & 0.4 & 110 & 1.3 & 0.4 \\
\hline Triglycerides (mmol/L) & 175 & 1.4 & 0.9 & 100 & 1.3 & 0.9 \\
\hline Height (cm), men & 126 & 176.6 & 7.9 & - & - & - \\
\hline Height $(\mathrm{cm})$, women & 68 & 165.5 & 7.7 & - & - & - \\
\hline Weight (kg), men & 123 & 80.0 & 15.7 & 66 & 86.0 & 17.6 \\
\hline Weight $(\mathrm{kg})$, women & 64 & 71.3 & 19.4 & 43 & 73.2 & 19.3 \\
\hline $\mathrm{BMI}\left(\mathrm{kg} / \mathrm{m}^{2}\right)$, men & 119 & 25.5 & 4.6 & 57 & 27.2 & 5.3 \\
\hline $\mathrm{BMI}\left(\mathrm{kg} / \mathrm{m}^{2}\right)$, women & 61 & 26.0 & 6.3 & 36 & 26.6 & 5.4 \\
\hline $\mathrm{HbA}_{1 \mathrm{c}}(\mathrm{mmol} / \mathrm{mol})$ & 167 & 35.5 & 7.1 & 93 & 37.7 & 8.3 \\
\hline Fasting glucose $(\mathrm{mmol} / \mathrm{L})$ & 173 & 4.8 & 0.9 & 95 & 5.1 & 1.9 \\
\hline C-reactive protein (mg/L) & 168 & 1 & $0.3-2.6$ & 93 & 1.5 & $0.5-3.5$ \\
\hline Insulin (mU/L) $)^{a}$ & 125 & 10.1 & $5.2-15.3$ & 60 & 8.8 & $5.0-14.6$ \\
\hline HOMA IR ${ }^{a, b}$ & 121 & 2.1 & $1.2-3.2$ & 57 & 1.8 & $1.0-2.7$ \\
\hline AUDIT hazardous drinking score & 199 & 9.4 & 9.5 & 115 & 5.8 & 6.9 \\
\hline DINE fat intake score & 186 & 32.8 & 13.5 & 114 & 30.7 & 13.2 \\
\hline IPAQ, mean h sitting per day & 178 & 8.1 & 4.2 & 110 & 8.3 & 4.2 \\
\hline PANSS total score ${ }^{\mathrm{c}}$ & 190 & 58.2 & 15.0 & 114 & 51.0 & 15.6 \\
\hline GAF symptoms score & 175 & 51.3 & 20.5 & 116 & 62.9 & 17.5 \\
\hline GAF disability score & 174 & 56.6 & 18.1 & 115 & 64.8 & 17.8 \\
\hline CGI severity scale score ${ }^{a}$ & 198 & 3 & $2-4$ & 116 & 2 & $1-4$ \\
\hline CGI improvement scale score ${ }^{a}$ & - & - & - & 111 & 1 & $0-2$ \\
\hline Calgary Depression Scale total score ${ }^{a, c}$ & 187 & 4 & $1-9$ & 118 & 3 & $1-8$ \\
\hline YMRS score ${ }^{a, c}$ & 185 & 4 & $2-8$ & 117 & 2 & $0-5$ \\
\hline \multicolumn{7}{|c|}{$\begin{array}{l}\text { S.d., standard deviation; IQR, interquartile range; BMI, body mass index; HDA } 1 \text { c, haemoglobin } \mathrm{A}_{1 c} \text {; HOMA IR, homeostasis model aSsessment - insulin resistance; AUDIT, Alcohol Use } \\
\text { Disorders Identification Test; DINE, Dietary Instrument for Nutrition Education; IPAQ, International Physical Activity Questionnaire; PANSS, Positive and Negative Symptom Scale; GAF, Global } \\
\text { Assessment of Functioning; CGI, Clinical Global Impression Scale; YMRS, Young Mania Rating Scale. } \\
\text { a. Medians and upper/lower quartiles presented instead of means standard deviations because of skewed data. } \\
\text { b. Values of fasting glucose over } 11 \text { mmol/L were excluded from the calculation of HOMA IR. } \\
\text { c. PANSS, Calgary and YMRS totals were calculated even where individual items were missing (although PANSS was considered missing if any of the three subscale totals, positive } \\
\text { symptoms, negative symptoms and general psychopathology were entirely missing). }\end{array}$} \\
\hline
\end{tabular}

Sensitivity analyses using complete cases only gave similar results with no evidence of any associations. Sensitivity analyses using a reduced data-set prior to imputing also gave similar results.

\section{Effects of gender and ethnicity}

Rates of central obesity at baseline were higher in women $(62.7 \%$, $n=37 / 59)$ than in men $(35.3 \%, n=36 / 102),\left(\chi^{2}=11.34, P=0.001\right)$, with a trend towards women from Black and minority ethnic (BME) groups having larger waists than their White counterparts $(t=2.37, P=0.02)$, this gap increasing over time in the paired sample subgroup (supplementary Table 5 ). White men overall gained a mean of $4.9 \mathrm{~cm}$ in waist circumference over the year, whereas men from BME groups gained $1.6 \mathrm{~cm}$ (Table 3), with similar findings in the paired sample subgroup (supplementary Table 5). There was no relationship between ethnicity and BMI. There was a trend towards lower total cholesterol at 12 months $(P=0.04)$ in BME patients.

Although $\mathrm{HbA}_{1 \mathrm{c}}$ levels at baseline were comparable, BME patients exhibited a significant increase in median $\mathrm{HbA}_{1 \mathrm{c}}$ levels over 12 months $(P<0.01)$, rising by $3.3 \mathrm{mmol} / \mathrm{mol}$. In contrast, no change was evident in White patients (Table 3 ). Where only complete paired data-sets were included in the analysis, median $\mathrm{HbA}_{\mathrm{lc}}$ rose in White patients by $1.1 \mathrm{~mm} / \mathrm{mol}$ and by $3.3 \mathrm{mmol} / \mathrm{mol}$ in participants from BME groups (supplementary Table 5). $\mathrm{HbA}_{1 \mathrm{c}}$ levels above $39 \mathrm{mmol} / \mathrm{mol}$ were seen in $10 \%(4 / 40)$ of White participants and $34 \%(18 / 53)$ of those from BME groups at 12 months. There was no significant difference in ethnicity between those prescribed olanzapine and those not prescribed it $\left(\chi^{2}(3)=-3.10\right.$, $P=0.376)$.

\section{Discussion}

This comprehensive large-scale cohort study of patients with FEP prospectively considers the relationship between lifestyle factors, medication and cardiometabolic trajectories. Weight gain is the most obvious problem for many patients both cosmetically and for their health - here $17.8 \%$ were obese at onset, rising to $23.7 \%$ within 1 year. A case has recently been made for obesity to be recognised as a chronic disease ${ }^{27}$ to allow the preventative strategies needed at a population level; in psychosis, the rapidity of weight gain over the first year offers an unrivalled opportunity for prevention, with diet, exercise and medication being key targets. We noted high consumption of saturated fat, carbonated, high-sugar drinks, sweetened beverages and added salt. Calorie intake was further augmented by alcohol use (Table 2). Although neither fat intake nor alcohol use in the early weeks of psychosis predicted longer-term outcomes in our population, the Keeping the Body in Mind programme has successfully worked with dieticians and exercise physiologists to prevent weight gain using lifestyle interventions for all early in the disease process. ${ }^{28}$

We also found early emergence of glucose dysregulation; by 1 year twice as many people had $\mathrm{HbA}_{1 \mathrm{c}}$ levels at or above the American Diabetes Association glucose dysregulation range (Tables 1 and 2). Diabetes is highly predictive of cardiometabolic disease and can have an especially significant impact on health in 
Table 2 Rates of identified cardiometabolic and lifestyle risk factors at each time point

\begin{tabular}{|c|c|c|c|c|}
\hline & \multicolumn{2}{|c|}{ Baseline } & \multicolumn{2}{|c|}{12 months } \\
\hline & $n$ & $\%$ & $n$ & $\%$ \\
\hline \multicolumn{5}{|c|}{ Body mass index $\left(\mathrm{BMl}, \mathrm{kg} / \mathrm{m}^{2}\right)$} \\
\hline $\mathrm{BMl} \leq 25$ & 90 & 50.0 & 39 & 41.9 \\
\hline $\mathrm{BMI}>25$ and $\leq 30$ & 58 & 32.2 & 32 & 34.4 \\
\hline $\mathrm{BMI}>30$ & 32 & 17.8 & 22 & 23.7 \\
\hline \multicolumn{5}{|c|}{ High total cholesterol (>5 mmol/L) } \\
\hline Yes & 76 & 40.9 & 46 & 40.4 \\
\hline No & 110 & 58.1 & 68 & 59.6 \\
\hline \multicolumn{5}{|c|}{ Raised triglycerides ( $\geq 1.7 \mathrm{mmol} / \mathrm{L}$ ) } \\
\hline Yes & 47 & 26.9 & 34 & 34.0 \\
\hline No & 128 & 73.1 & 66 & 66.0 \\
\hline \multicolumn{5}{|c|}{ Low high-density lipoprotein cholesterol $^{a}$} \\
\hline Yes & 46 & 25.7 & 37 & 33.6 \\
\hline No & 133 & 74.3 & 73 & 66.4 \\
\hline \multicolumn{5}{|l|}{ Type 2 diabetes } \\
\hline Yes & 6 & 3.4 & 5 & 5.0 \\
\hline No & 172 & 96.6 & 94 & 95.0 \\
\hline \multicolumn{5}{|l|}{$\mathrm{HbA}_{1 \mathrm{c}} \geq 39 \mathrm{mmol} / \mathrm{mol}$} \\
\hline Yes & 20 & 12.0 & 22 & 23.7 \\
\hline No & 147 & 88.0 & 71 & 76.3 \\
\hline \multicolumn{5}{|l|}{ C-reactive protein } \\
\hline$>3 \mathrm{mg} / \mathrm{L}$ & 37 & 22.0 & 28 & 30.1 \\
\hline$\leq 3 \mathrm{mg} / \mathrm{L}$ & 131 & 78.0 & 65 & 69.9 \\
\hline \multicolumn{5}{|l|}{ Hypertension } \\
\hline Yes & 33 & 15.1 & 23 & 15.7 \\
\hline No & 186 & 84.9 & 124 & 84.3 \\
\hline \multicolumn{5}{|l|}{ IPAQ sitting hours } \\
\hline$\leq 6 \mathrm{~h}$ per day & 76 & 42.7 & 44 & 40.0 \\
\hline$>6$ and $\leq 10 \mathrm{~h}$ per day & 53 & 29.8 & 37 & 33.6 \\
\hline$>10 \mathrm{~h}$ per day & 49 & 27.5 & 29 & 26.4 \\
\hline \multicolumn{5}{|c|}{$\begin{array}{l}\text { Minutes of moderate or vigorous exercise per } \\
\text { week }\end{array}$} \\
\hline$<150$ & 144 & 77.0 & 70 & 60.0 \\
\hline$\geq 150$ & 43 & 23.0 & 46 & 40.0 \\
\hline \multicolumn{5}{|l|}{ DINE score (saturated fat) } \\
\hline$\leq 40$ & 137 & 74.0 & 91 & 79.8 \\
\hline$>40$ & 49 & 26.0 & 23 & 20.2 \\
\hline \multicolumn{5}{|c|}{ AUDIT hazardous drinking score } \\
\hline$>7$ & 96 & 48.2 & 33 & 28.7 \\
\hline$\leq 7$ & 102 & 51.8 & 82 & 71.3 \\
\hline \multicolumn{5}{|l|}{ Current smoker? } \\
\hline Yes & 139 & 76.8 & 66 & 73.3 \\
\hline $\begin{array}{l}\text { HDA }{ }_{1 c} \text {, haemoglobin } A_{1 c} ; \mathrm{IPAC} \\
\text { Dietary Instrument for Nutritio } \\
\text { Test. } \\
\text { a. Men: }<1.03 \mathrm{mmol} / \mathrm{L} ; \text {; womer }\end{array}$ & $\begin{array}{l}\text { vity Que } \\
\text { I Use Dis }\end{array}$ & $\begin{array}{l}\text { stionnai } \\
\text { sorders }\end{array}$ & $\begin{array}{l}\text { Ire; DINE } \\
\text { Identific }\end{array}$ & \\
\hline
\end{tabular}

people with psychosis, given the other practical challenges they may face.

There was a remarkably high baseline prevalence of tobacco smoking of $76.8 \%$. Smoking confers an almost fivefold risk of mortality in people with schizophrenia. ${ }^{29}$ Further, nicotine dependence after psychosis onset predicts both poor medication adherence and non-remission of psychosis. ${ }^{30}$ It is therefore worrisome that we saw little reduction in smoking rates over time. Since this work was completed, many UK mental health hospitals have become smoke-free environments ${ }^{31}$ and although a recent trial has demonstrated that smoking cessation can be achieved in the community, work remains to be done to sustain quitting. ${ }^{32}$ Rates of current cannabis use and lifetime use of other substances were high, in keeping with previous work. ${ }^{22}$

People with psychosis engage in low levels of physical activity. ${ }^{33}$ Although physical activity at baseline did not predict cardiometabolic outcome in our study, by 12 months $40 \%$ of the participants were engaging in the 150 min of physical activity per week recommended by the WHO (2014). ${ }^{34}$ Worryingly however, sedentary behaviour changed little and CRP levels increased over time. Sedentary behaviour is associated with inflammation in psychosis, ${ }^{35}$ and inflammation is in turn linked to cardiometabolic disease. ${ }^{36}$ Both exercise and sedentary behaviour are important targets for health promotion with studies underway to examine ways of changing patterns of behaviour in clinical settings. ${ }^{37}$

Our regression analyses revealed no relationship between cardiometabolic outcomes and lifestyle, nor any effect of dibenzodiazepine medication, despite the high risk of weight gain demonstrated with olanzapine in other settings. ${ }^{3}$ A high proportion were prescribed olanzapine as a first antipsychotic, a practice now not recommended..$^{38}$ Of note, no participants were prescribed clozapine in the first year of their illness, in keeping with the reported mean lag time to starting clozapine of 47.7 months (s.d. $=49.7) .{ }^{39}$ The omission of clozapine is noteworthy as $23 \%$ of people presenting with their first episode of psychosis are treatment resistant from illness onset. $^{40}$

Our sensitivity analyses illustrated the rapidity of cardiometabolic change in early psychosis; those exposed to antipsychotic medication for more than 14 days before baseline had higher cholesterol levels than those on antipsychotics for less than a fortnight, and those exposed to any antipsychotic medication had a larger waist circumference at baseline than did individuals who were antipsychotic naive.

\section{Effects of ethnicity and gender}

Men of White ethnicity appeared to have a particular vulnerability to emergence of central obesity, increasing their mean waist size by $4.9 \mathrm{~cm}$, whereas men of other ethnicities gained a more modest $1.6 \mathrm{~cm}$. These changes are clinically significant and the variation between ethnic groups was in keeping with findings in established psychosis. ${ }^{41}$ Central obesity is a better predictor of CVD risk than is general obesity, ${ }^{42}$ so this may relate to the lower hazard ratios seen for all-cause mortality in Black African, Black Caribbean and South Asian patients with severe mental illness compared with their White British counterparts. ${ }^{43}$

Women were at risk of central obesity throughout, with $72.7 \%$ in that category by 1 year, again consistent with the local figure of $95 \%$ seen in women with established psychosis. ${ }^{41}$ Central adiposity in women is predictive of all-cause mortality in White, but not Black women. ${ }^{44}$

Minority ethnic groups appeared vulnerable to emergent glucose dysregulation, with highly clinically relevant increases in median $\mathrm{HbA}_{1 \mathrm{c}}$ of $3.3 \mathrm{mmol} / \mathrm{mol}$ (Table 3 and supplementary Table 5), but no change seen in White patients. Within the non-diabetic range, this reflects a highly clinically significant shift in glycaemia in the BME group, with one-third exceeding the American Diabetes Association $\mathrm{HbA}_{1 \mathrm{c}}$ threshold for pre-diabetes ${ }^{15}$ ( $>39 \mathrm{mmol} / \mathrm{mol}$ $(5.7 \%)$ ), although it is useful to note that some would not have been identified as at risk by current National Institute for Health and Care Excellence guidelines. ${ }^{45}$ This change in glucose regulation in a relatively young population over just 1 year highlights the risk of accelerated emergence of diabetes in people of ethnicities other than White, and is in keeping with a recent large cross-sectional analysis of London primary care ${ }^{46}$ data that showed a three- to tenfold relative risk of type 2 diabetes in young people with severe mental illness.

\section{Strengths and limitations}

This is to our knowledge the most comprehensive study to date examining the effects of lifestyle choice on emergent cardiometabolic risk. In conducting this study, we recruited an incident sample of people presenting to both in-patient and community services for the first time with psychosis and we followed them up for 1 year, thereby capturing the period with the greatest change in physical 

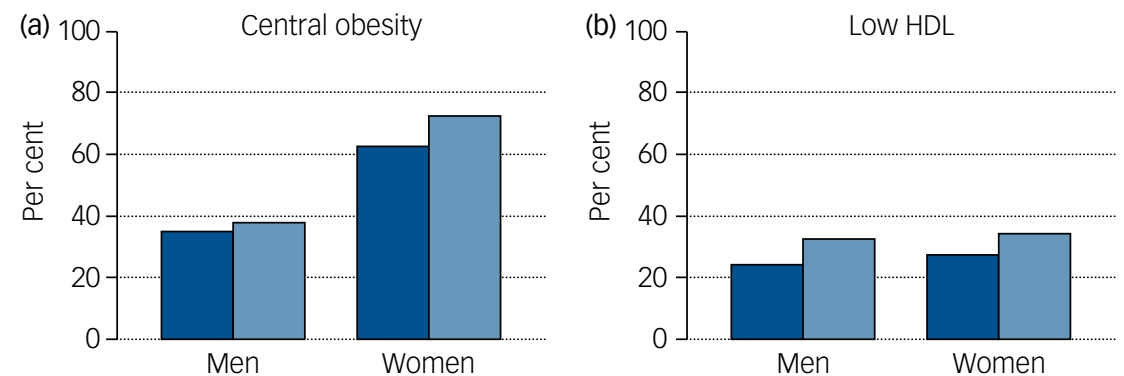

Baseline

12 months
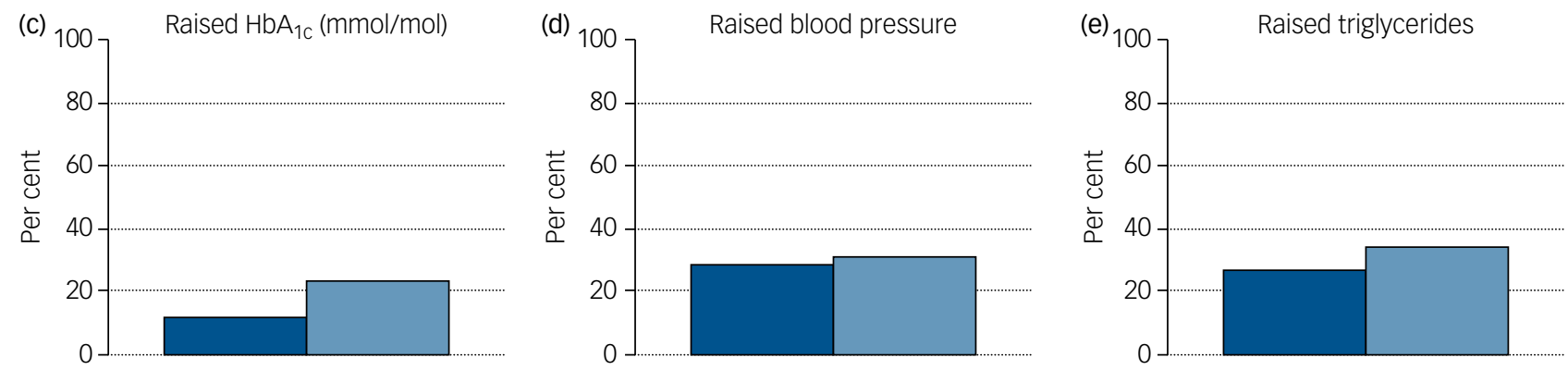

Fig. 1 Rates of identified cardiometabolic risk at each time point.

(a) Central obesity; (b) low high-density lipoprotein (HDL); (c) raised haemoglobin $\mathrm{HbA}_{1 c}$; (d) raised blood pressure; and (e) raised triglycerides.

Table 3 Effects of gender and ethnicity

\begin{tabular}{|c|c|c|c|c|c|c|}
\hline & Men & Women & $\begin{array}{l}\text { Difference } \\
\text { by gender }\end{array}$ & White & Other ethnicity & $\begin{array}{c}\text { Difference } \\
\text { by ethnicity }\end{array}$ \\
\hline \multicolumn{7}{|c|}{ Body mass index $\left(\mathrm{kg} / \mathrm{m}^{2}\right)$, mean (s.d.) } \\
\hline Baseline $(n=180)$ & $25.5(4.6)$ & $26.0(6.3)$ & -0.5 & $25.7(5.4)$ & $25.7(5.1)$ & 0.0 \\
\hline 12 months $(n=93)$ & $27.2(5.3)$ & $26.6(5.4)$ & 0.6 & $26.9(5.6)$ & $27.0(5.1)$ & -0.1 \\
\hline \multicolumn{7}{|c|}{ Total cholesterol (mmol/L), mean (s.d.) } \\
\hline Baseline $(n=186)$ & $4.81(1.05)$ & $4.80(0.83)$ & 0.01 & $4.93(1.12)$ & $4.70(0.82)$ & 0.23 \\
\hline 12 months $(n=114)$ & $4.81(1.22)$ & $4.82(0.92)$ & -0.01 & $5.05(1.36)$ & $4.62(0.80)$ & 0.43 \\
\hline \multicolumn{7}{|c|}{$\mathrm{HbA}_{1 \mathrm{c}}(\mathrm{mmol} / \mathrm{mol})$, median (upper and lower quartiles) } \\
\hline Baseline $(n=167)$ & $34.4(32.2-37.7)$ & $33.3(32.2-35.5)$ & 1.1 & $34.4(32.2-36.6)$ & $34.4(32.8-37.7)$ & 0.0 \\
\hline 12 months $(n=93)$ & $36.6(34.4-39.9)$ & $36.6(33.3-38.8)$ & 0.0 & $34.4(33.3-37.2)$ & $37.7(35.5-39.9)$ & -3.3 \\
\hline \multicolumn{7}{|c|}{ Current smoking (\%) (at least once a week) } \\
\hline Baseline $(n=181)$ & 79.8 & 70.2 & 9.6 & 79.2 & 74.1 & 5.1 \\
\hline 12 months $(n=90)$ & 76.8 & 67.7 & 9.1 & 75.5 & 70.7 & 4.8 \\
\hline \multicolumn{7}{|c|}{ Mean waist circumference (cm), mean (s.d.) } \\
\hline \multicolumn{7}{|l|}{ Men } \\
\hline Baseline $(n=102)$ & - & - & - & $92.5(13.6)$ & $88.5(10.6)$ & 4.0 \\
\hline 12 months $(n=66)$ & - & - & - & $97.4(15.6)$ & $90.1(11.1)$ & 7.3 \\
\hline \multicolumn{7}{|l|}{ Women } \\
\hline Baseline $(n=59)$ & - & - & - & $84.1(13.3)$ & $93.7(17.6)$ & -9.6 \\
\hline 12 months $(n=44)$ & - & - & - & $86.1(16.9)$ & $92.9(16.4)$ & -6.8 \\
\hline
\end{tabular}

Table 4 Association between lifestyle factors at baseline and 12-month change in cardiometabolic risk factors (adjusted for age, gender, ethnicity and pre-baseline number of days on antipsychotic medication)

\begin{tabular}{|c|c|c|c|c|}
\hline \multirow[b]{2}{*}{$\begin{array}{l}\text { Dependent (response) variable/independent } \\
\text { variable }^{\text {a }}\end{array}$} & \multicolumn{4}{|c|}{ Coefficient $(95 \% \mathrm{Cl})$} \\
\hline & $\begin{array}{l}\text { Baseline DINE } \\
\text { fat score }\end{array}$ & $\begin{array}{l}\text { Baseline AUDIT } \\
\text { hazardous } \\
\text { drinking score }\end{array}$ & $\begin{array}{l}\text { Baseline number } \\
\text { of } h \text { sitting per day }\end{array}$ & $\begin{array}{l}\text { OLZ versus not OLZ } \\
\text { between baseline } \\
\text { and } 12 \text { months }\end{array}$ \\
\hline 12-month change in cholesterol (mmol/mol) & $0.008(-0.088$ to 0.025$)$ & $0.009(-0.018$ to 0.036$)$ & $0.023(-0.032$ to 0.077$)$ & $-0.247(-0.738$ to 0.245$)$ \\
\hline $\begin{array}{l}\text { 12-month change in diastolic blood pressure } \\
\text { (mmHg) }\end{array}$ & $-0.029(-0.192$ to 0.134$)$ & $0.045(-0.252$ to 0.341$)$ & 0.039 (-0.585 to 0.592$)$ & $-0.425(-5.085$ to 4.235$)$ \\
\hline 12-month change in $\mathrm{HbA}_{1 \mathrm{c}}(\mathrm{mol} / \mathrm{mmol})$ & $-0.005(-0.145$ to 0.155$)$ & $0.137(-0.049$ to 0.324$)$ & $-0.141(-0.613$ to 0.330$)$ & -0.552 ( -3.408 to 3.298$)$ \\
\hline 12-month change in waist circumference $(\mathrm{cm})$ & $0.034(-0.167$ to 0.235$)$ & $0.042(-0.329$ to 0.412$)$ & $-0.233(-1.172$ to 0.707$)$ & $0.326(-4.712$ to 5.364$)$ \\
\hline 12-month change in body mass index $\left(\mathrm{kg} / \mathrm{m}^{2}\right)$ & $-0.003(-0.108$ to 0.103$)$ & $0.019(-0.143$ to 0.181$)$ & $-0.058(-0.415$ to 0.299$)$ & $0.437(-2.094$ to 2.968$)$ \\
\hline $\begin{array}{l}\text { 12-month change in high-density lipoproteins } \\
(\mathrm{mmol} / \mathrm{L})\end{array}$ & $-0.001(-0.008$ to 0.007$)$ & $0.001(-0.009$ to 0.011$)$ & $0.002(-0.021$ to 0.024$)$ & $-0.084(-0.259$ to 0.090$)$ \\
\hline 12-month change in triglycerides (mmol/L) & $0.005(-0.010$ to 0.021$)$ & $0.006(-0.020$ to 0.032$)$ & $0.010(-0.053$ to 0.072$)$ & $0.051(-0.389$ to 0.491$)$ \\
\hline
\end{tabular}


health. The diverse nature of the population studied allows exploration of the effect of ethnicity on emergence of cardiometabolic risk. The use of multiple imputation on a reduced data-set allowed confidence in the results while retaining generalisability. ${ }^{47}$

The study must be interpreted taking into account a number of methodological aspects. Over half our patients required acute inpatient care at the time of recruitment and many had received treatment for some weeks before being well enough to consent to inclusion. To minimise this effect and minimise missing data, we therefore sought permission to use clinical data, where available and comparable, as well as adjusting for the number of days prescribed antipsychotics before baseline in our analyses. Also, in follow-up studies there is a risk that attrition may not be random. Therefore, considerable efforts were made to minimise loss to follow-up with contact made with $81 \%(217 / 268)$ of the then eligible participants at 12 months, although 73 participants declined 12-month follow-up. There was recompense for time but no financial incentivisation to remain in the study. Analysis showed no differences in baseline demographic or clinical attributes between completers and non-completers. The supplementary tables include a descriptive table of complete paired measures. We also note that although 89 people were prescribed olanzapine at baseline, some did not sustain that prescription throughout the study period, possibly because of emergent metabolic effects. Finally, the number of statistical tests carried out was reasonably large and although we took a more conservative threshold of statistical significance, we cannot completely discount the possibility of type I errors.

In conclusion, our results identify that cardiometabolic risk factors are already pronounced in those presenting to FEP services and worsen over the first year under standard care. No baseline behaviour predicted risk of worsening cardiometabolic parameters, but a greater degree of emergent glucose dysregulation was observed in those from BME groups.

Fiona Gaughran, MD, FRCP(I), FRCP, FRCP(Edin), FRCPsych, Lead Consultant Psychiatrist, National Psychosis Service, South London and Maudsley NHS Foundation Trust; and Reader, Department of Psychosis Studies, Institute of Psychiatry, Psychology and Neuroscience, Kings College London, Denmark Hill, UK; Daniel Stahl, Professor in Medical Statistics and Statistical Learning, Department of Biostatistics and Health Informatics, Institute of Psychiatry, Psychology and Neuroscience, Kings College London, UK; Dominic Stringer, Statistician, Department of Biostatistics and Health Informatics, Institute of Psychiatry, Psychology and Neuroscience, Kings College London, UK: David Hopkins, BSC, MB, ChB, FRCP, Consultant Diabetologist, Institute Director and Clinical Academic Group Lead, Institute of Diabetes, Endocrinology and Obesity, King's Health Partners, UK; Zerrin Atakan, MD, FRCPsych Hon., Senior Lecturer, Department of Psychosis Studies, Institute of Psychiatry, Psychology and Neuroscience, Kings College London, UK; Kathryn Greenwood, PhD, DClinPsy, Professor of Clinical Psychology, School of Psychology, University of Sussex, UK; Anita Patel, PhD, MSC, BSc, Director Anita Patel Health Economics Consulting Ltd; and Honorary Professor, Queen Mary University of London, UK; Shubulade Smith, MBBS, MD, FRCPsych, Clinical Senior Lecturer, Department of Forensic and Neurodevelopmental Science, Institute of Psychiatry, Psychology and Neuroscience, Kings College London; and Consultant Psychiatrist, Forensic Services, South London and Maudsley NHS Foundation Trust, UK: Poonam Gardner-Sood, PhD, Clinical Trials Manager, University College London, UK; John Lally (D), MB, MSc, MRCPsych, Visiting Researcher, Department of Psychosis Studies, Institute of Psychiatry, Psychology and Neuroscience, King's College London, UK; and the Royal College of Surgeons in Ireland; Margaret Heslin (1D, PhD, Research Fellow and Honorary Lecturer, Kings' Health Economics, Institute of Psychiatry, Psychology and Neuroscience, King's College London, UK; Brendon Stubbs, PhD, BSc (Hons), MSC, MCSP, NIHR Lecturer, Department of Psychological Medicine, Institute of Psychiatry, King's College London; and Head of Physiotherapy, Physiotherapy Department, South London and Maudsley NHS Foundation Trust, UK; Stefania Bonaccorso, MD, PhD, DSC, Consultant Psychiatrist, C\&I Foundation Trust; and Visiting Lecturer, Department of Psychosis Studies, Institute of Psychiatry, Psychology and Neuroscience, Kings College London, UK; Anna Kolliakou, PhD, Clinical Informatics Interface and Network Lead, Department of Psychological Medicine, Institute of Psychiatry, Psychology and Neuroscience, Kings College London, UK; Oliver Howes, MB, PhD, Professor of Molecular Psychiatry, MRC London Institute for Medical Sciences; and Institute of Psychiatry, Psychology and Neuroscience, Kings College London; and the South London and Maudsley NHS Foundation Trust, UK; David Taylor, BSC, MSC, PhD, FFRPS, FRPharms, Director of Pharmacy and Pathology and Head of Pharmaceutical Sciences Clinical Academic Group, King's Health Partners, South London and Maudsley NHS Foundation Trust, UK; Marta Di Forti, MD, PhD, MRC Clinician Scientist, Department of Social, Genetic and Developmental Psychiatry, Institute of Psychiatry, Psychology and Neuroscience, Kings College London; the South London and Maudsley NHS Foundation Trust, UK; and Department of Psychiatry, Experimental Biomedicine and Clinical Neuroscience (BIONEC), University of Palermo, Italy; Anthony S. David, FRCPsych, FR $\mathrm{CP}, \mathrm{MD}$, Professor of Mental Health, Director and Sackler Chair, Institute of Mental Health, Division of Psychiatry, University College London, UK; Robin M. Murray, FRS, Professor of Psychiatric Research, Department of Psychosis Studies, Institute of Psychiatry,
Psychology and Neuroscience, Kings College London; the South London and Maudsley NHS Foundation Trust, UK; and Department of Psychiatry, Experimental Biomedicine and Clinical Neuroscience (BIONEC), University of Palermo, Italy; Khalida Ismail, Mb, PhD, Professor of Psychiatry and Medicine, Department of Psychological Medicine, Institute of Psychiatry, Psychology and Neuroscience, Kings College London, UK; the IMPACT team (listed in the Acknowledgements)

Correspondence: Fiona Gaughran, W1.08, Institute of Psychiatry, Psychology and Neuroscience (IOPPN), King's College London, De Crespigny Park, London SE5 8AF, UK. Email: Fiona.p.gaughran@kcl.ac.uk

First received 19 Jan 2018, final revision 29 May 2019, accepted 1 Jun 2019

\section{Funding}

This paper summarises independent research funded by the National Institute for Health Research (NIHR) under its IMPACT Programme (Grant Reference Number RP-PG-0606-1049) in collaboration with Genetics and Psychosis Project funded by the NIHR Biomedical Research Centre at South London and Maudsley NHS Foundation Trust and King's College London. B.S. and F.G. are, in part, supported by the Maudsley Charity and the NIHR Collaboration for Leadership in Applied Health Research and Care South London (NIHR CLAHRC South London) at King's College Hospital NHS Foundation Trust. B.S. is supported by a Clinical Lectureship (ICA-CL-2017-03-001) jointly funded by Health Education England (HEE) and the NIHR. D.S. was part-funded by the NIHR Biomedical Research Centre at South London and Maudsley NHS Foundation Trust and King's College London. The views expressed in this publication are those of the authors and not necessarily those of the NHS, the NIHR or the Department of Health

\section{Acknowledgements}

Members of the IMPACT team are: Maurice Arbuthnott, Bee Harries, Philippa Lowe, Susan Moore, Conan O'Brien, Ali Featherman, Catherine Fung, Margaret Heslin, Keji Dalemo, Stella Anakwe-Umeh, Gill Todd, Manyara Mushore, Diana Orr, Ruth Ohlsen, Evangelos Papanastasiou, Mudasir Firdosi, Hannah Sallis, Irene Sambath, Guilia Di Clemente, Josefine Breedvelt, Hugh Williams, Candice Joseph, Jonas Eberhard and Marco Colizzi.

\section{Supplementary material}

Supplementary material is available online at https://doi.org/10.1192/bjp.2019.159.

\section{References}

1 Olfson M, Gerhard T, Huang C, Crystal S, Stroup TS. Premature mortality among adults with schizophrenia in the United States. JAMA Psychiatry 2015; 72: 1172-81.

2 Pillinger T, Beck K, Gobjila C, Donocik JG, Jauhar S, Howes OD. Impaired glucose homeostasis in first-episode schizophrenia: a systematic review and metaanalysis. JAMA Psychiatry 2017; 74: 261-9.

3 Fleischhacker WW, Siu CO, Bodén R, Pappadopulos E, Karayal ON, Kahn RS. Metabolic risk factors in first-episode schizophrenia: baseline prevalence and course analysed from the European First-Episode Schizophrenia Trial. Int J Neuropsychopharmacol 2013; 16: 987-95.

4 Howes O, Bhatnagar A, Gaughran F, Amiel S, Pilowsky L, Murray R. A prospective study of changes in glucose control caused by clozapine without changes in insulin resistance. Am J Psychiatry 2004; 161: 361-3.

5 Tek C, Kucukgoncu S, Guloksuz S, Woods SW, Srihari VH, Annamalai A. Antipsychotic-induced weight gain in first-episode psychosis patients: a metaanalysis of differential effects of antipsychotic medications. Early Interv Psychiatry 2016; 10: 193-202.

6 Nyboe L, Vestergaard $\mathrm{CH}$, Moeller MK, Lund H, Videbech P. Metabolic syndrome and aerobid fitness in patients with first episode schizophrenia, including a 1-year follow-up. Schizophr Res 2015; 168(1-2): 381-7.

7 World Health Organization. The ICD-10 Classification of Mental and Behavioural Disorders: Clinical Descriptions and Diagnostic Guidelines. WHO, 1992.

8 Craddock N, Asherson P, Owen MJ, Williams J, McGuffin P, Farmer AE. Concurrent validity of the OPCRIT diagnostic system. Comparison of OPCRIT diagnoses with consensus best-estimate lifetime diagnoses. Br J Psychiatry 1996; 169: 58-63.

9 Kay SR, Fiszbein A, Opler LA. The Positive and Negative Syndrome Scale (PANSS) for schizophrenia. Schizophr Bull 1987; 13: 261-76.

10 Richard CW, Hall MD. Global assessment of functioning: a modified scale. Psychosomatics 1995; 36: 267-75.

11 Guy W. Clinical Global Impressions (CGI) Scale, Modified. In Task Force for the Handbook of Psychiatric Measures. Handbook of Psychiatric Measures (1st edn) (ed JA Rush). American Psychiatric Association, 2000. 
12 Addington D, Addington J, Schissel B. A depression rating scale for schizophrenics. Schizophr Res 1990; 3: 247-51.

13 Young RC, Biggs JT, Ziegler VE, Meyer DA. A rating scale for mania: reliability validity and sensitivity. Br J Psychiatry 1978; 133: 429-35.

14 World Health Organization. Overweight and Obesity in Adults. WHO, 2015 (http://www who.int/healthinfo/indicators/2015/ chi_2015_67_adults_overweight.pdf?ua=)

15 American Diabetes Association. Standards of Medical Care in Diabetes. Diabetes Care 2017; 40 (suppl 1): 1-142.

16 Alberti KG, Zimmet $P$, Shaw J. Metabolic syndrome-a new world-wide definition. A Consensus Statement from the International Diabetes Federation. Diabet Med 2006; 23: 469-80.

17 Craig CL, Marshall AL, Sjöström M, Bauman AE, Booth ML, Ainsworth BE, et al. International physical activity questionnaire: 12-country reliability and validity. Med Sci Sports Exerc 2003; 35: 1381-95.

18 Faulkner G, Cohn T, Remington G. Validation of a physical activity assessment tool for individuals with schizophrenia. Schizophr Res 2006; 82: 225-31.

19 Roe L, Strong C, Whiteside C, Neil A, Mant D. Dietary intervention in primary care: validity of the DINE method for diet assessment. Fam Pract 1994; 11: 375-81.

20 Fagerstrom KO. Measuring degree of physical dependence to tobacco smoking with reference to individualization of treatment. Addict Behav 1978; 3: 235-41.

21 Saunders J, Aasland OG, Babor TF, de la Fuente JR, Grant M. Development of the Alcohol Use Disorders Identification Test (AUDIT): WHO collaborative project on early detection of persons with harmful alcohol consumption-ll. Addiction 1993; 88: 791-804.

22 Di Forti M, Morgan C, Dazzan P, Pariante C, Mondelli V, Marques TR, et al. Highpotency cannabis and the risk of psychosis. Br J Psychiatry 2009; 195: 488-91.

23 Barkus EJ, Stirling J, Hopkins RS, Lewis S. Cannabis-induced psychosis-like experiences are associated with high schizotypy. Psychopathology 2006; 39 $175-8$

24 White IR, Daniel R, Royston P. Avoiding bias due to perfect prediction in multiple imputation of incomplete categorical data. Comput Stat Data Anal 2010 54: 2267-75.

25 Schencker N, Taylor JMG. Partially parametric techniques for multiple imputation. Comput Stat Data Anal 1996; 22: 425-46.

26 Lang TA, Secic M. How to Report Statistics in Medicine: Annotated Guidelines for Authors, Editors, and Reviewers (2nd edn). American College of Physician Press, 2006.

27 Bray GA, Kim KK, Wilding JPH. Obesity: a chronic relapsing progressive disease process. A position statement of the World Obesity Federation. Obes Rev 2017 18: $715-23$.

28 Curtis J, Watkins A, Rosenbaum S, Teasdale S, Kalucy M, Samaras K, et al. Evaluating an individualized lifestyle and life skills intervention to prevent antipsychotic-induced weight gain in first-episode psychosis. Early Interv Psychiatry 2016; 10: 267-76.

29 Dickerson F, Stallings C, Origoni A, Schroeder J, Khushalani S, Yolken R Mortality in schizophrenia: clinical and serological predictors. Schizophr Bull 2014; 40: 796-803

30 Colizzi M, Carra E, Fraietta S, Lally J, Quattrone D, Bonaccorso S, et al. Substance use, medication adherence and outcome one year following a first episode of psychosis. Schizophr Res 2016; 170: 311-7.

31 Robson D, Spaducci G, McNeill A, Stewart D, Craig TJK, Yates M, et al. Effect of implementation of a smoke-free policy on physical violence in a psychiatric inpatient setting: an interrupted time series analysis. Lancet Psychiatry 2017 4: $540-6$
32 Gilbody S, Peckham E, Bailey D, Arundel C, Heron P, Crosland S, et al. Smoking cessation for people with severe mental illness (SCIMITAR+): a pragmatic randomised controlled trial. Lancet Psychiatry 2019; 6: 379-90.

33 Stubbs B, Williams J, Gaughran F, Craig T. How sedentary are people with psychosis? A systematic review and meta-analysis. Schizophr Res 2016; 171: 103-9.

34 World Health Organization. Physical Activity and Adults. WHO, accessed 2019 (https://www.who.int/dietphysicalactivity/factsheet_adults/en/).

35 Stubbs B, Gardner-Sood P, Smith S, Ismail K, Greenwood K, Farmer R, et al. Sedentary behaviour is associated with elevated $\mathrm{C}$-reactive protein levels in people with psychosis. Schizophr Res 2015; 168: 461-4.

36 Vepsäläinen $\mathrm{T}$, Soinio $\mathrm{M}$, Marniemi J, Lehto $\mathrm{S}$, Juutilainen $\mathrm{A}$, Laakso $\mathrm{M}$, et al. Physical activity, high-sensitivity C-reactive protein, and total and cardiovascular disease mortality in type 2 diabetes. Diabetes Care 2011; 34: 1492-6.

37 Williams J, Stubbs B, Gaughran F, Craig T. 'Walk This Way' - a pilot of a health coaching intervention to reduce sedentary behaviour and increase low intensity exercise in people with serious mental illness: study protocol for a randomised controlled trial. Trials 2016; 17: 594.

38 Buchanan RW, Kreyenbuhl J, Kelly DL, Noel JM, Boggs DL, Fischer BA, et al. The 2009 schizophrenia PORT psychopharmacological treatment recommendations and summary statements. Schizophr Bull; 2010; 36: 71-93.

39 Howes OD, Vergunst F, Gee S, McGuire P, Kapur S, Taylor D. Adherence to treatment guidelines in clinical practice: study of antipsychotic treatment prior to clozapine initiation. Br J Psychiatry 2012; 201: 481-5.

40 Lally J, Ajnakina O, Di Forti M, Trotta A, Demjaha A, Kolliakou A, et al. Two distinct patterns of treatment resistance: clinical predictors of treatment resistance in first-episode schizophrenia spectrum psychoses. Psychol Med 2016; 46: 3231-40.

41 Gardner-Sood P, Lally J, Smith S, Atakan Z, Ismail K, Greenwood KE, et al. Cardiovascular risk factors and metabolic syndrome in people with established psychotic illnesses: baseline data from the IMPaCT randomized controlled trial. Psychol Med 2015; 45: 2619-29.

42 Goh LG, Dhaliwal SS, Welborn TA, Lee AH, Della PR. Anthropometric measurements of general and central obesity and the prediction of cardiovascular disease risk in women: a cross-sectional study. BMJ Open 2014; 4: e004138.

43 Das-Munshi J, Chang CK, Dutta R, Morgan C, Nazroo J, Stewart R, et al. Ethnicity and excess mortality in severe mental illness: a cohort study. Lancet Psychiatry 2017; 4: 389-99.

44 Stevens J, Keil JE, Rust PF, Tyroler HA, Davis CE, Gazes PC. Body mass index and body girths as predictors of mortality in black and white women. Arch Intern Med 1992; 152: 1257-62.

45 National Institute for Health and Care Excellence. Type 2 Diabetes: Prevention in People at High Risk. NICE, 2012 ((https://www.nice.org.uk/guidance/PH38/ chapter/Recommendations\#risk-identification-stage-1)

46 Das-Munshi J, Ashworth M, Dewey ME, Gaughran F, Hull S, Morgan C, et al Type 2 diabetes mellitus in people with severe mental illness: inequalities by ethnicity and age. Cross-sectional analysis of 588408 records from the UK. Diabet Med 2017; 34: 916-24.

47 Stuart EA, Azur M, Frangakis C, Leaf P. Multiple imputation with large data sets: a case study of the Children's Mental Health Initiative. Am J Epidemiol 2009; 169: 1133-9. 